\title{
Do childhood respiratory infections continue to influence adult respiratory
} morbidity?

\author{
S.C. Dharmage*, B. Erbas*, D. Jarvis”, M. Wjst ${ }^{\dagger}$, C. Raherison+, D. Norbäck ${ }^{\S}$, \\ J. Heinrich", J. Sunyer ${ }^{f, * *, \# \#}$ and C. Svanes ${ }^{\text {"⿻ }}$
}

ABSTRACT: The aim of the present study was to examine the influence of childhood respiratory infections on adult respiratory health.

In 1992-1994, the European Community Respiratory Health Survey recruited community based samples of 20-44-yr-old people from 48 centres in 22 countries. Study participants completed questionnaires and underwent lung function testing. On average, 8.9 yrs later, 29 centres reinvestigated their samples using similar methods. Mixed effects models comprising an estimate for the random variation between centres were used to evaluate the relevant associations.

In total, 9,175 patients participated in both studies, of whom $10.9 \%$ reported serious respiratory infections (SRI) before 5 yrs of age and 2.8\% reported hospitalisation for lung disease (HLD) before 2 yrs if age. SRI was associated with current wheeze (odds ratio (OR) 1.9, 95\% confidence interval (CI) 1.7-2.2), asthma (OR 2.5, 95\% $\mathrm{Cl} 2.2-3.1$ ), and lower forced expiratory volume in one second (FEV1; $89 \mathrm{~mL}$; 95\% Cl 54-126), forced vital capacity (FVC; $49 \mathrm{~mL}$; 95\% Cl 8-90) and FEV1/ FVC ratio (-1.2\%; 95\% $\mathrm{Cl}-1.8--0.6)$. Childhood respiratory infections were also associated with new asthma (OR 1.5, 95\% Cl 1.03-2.0), new wheeze (OR 1.5, 95\% Cl 1.0-2.4) and persistent wheeze (OR $2.2,95 \% \mathrm{Cl}$ 1.4-3.6) but not with a decline in lung function. Similar findings were observed for HDL. These associations were significantly consistent across centres. SRI was associated with lower FEV1 when excluding ever asthmatics and current wheezers. The impact of early infections was significantly larger in subjects exposed to maternal or active smoking.

The impact of childhood respiratory infections on the respiratory system may not only last into adulthood but also influence development and persistence of adult respiratory morbidity.

KEYWORDS: Adult asthma, adult lung function, childhood respiratory infections

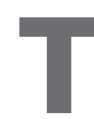
he impact of severe childhood respiratory infections on childhood asthma and lung function has been established. However, their implications on adult respiratory morbidity are still uncertain. This is mainly related to the scarcity of longitudinal studies investigating these associations beyond childhood.

A recent review suggests the host response rather than the infecting organism of childhood respiratory infections is the best predictor of consequences on respiratory health [1]. Having recurrent chest illness, viral bronchiolitis, lower respiratory infections and doctor-treated airway disease during the first 2-3 yrs of age have been identified as predictors of childhood asthma [27], poor lung function [4,8] and impaired lung growth [4]. Some studies have found that the association between early respiratory infections and childhood respiratory morbidity is stronger among males [4, 8], while in the current study it was found to be stronger among females [9]. Only a few studies have examined respiratory repercussions of early childhood respiratory infections in adults. These have found viral bronchiolitis during infancy and childhood pneumonia to be associated with respiratory symptoms and lower lung function in young adults [5, 10-14]. SHAHEEN et al. [15] showed that pneumonia before age $2 \mathrm{yrs}$ is related to lower forced expiratory volume in one second (FEV1) in elderly males. Furthermore, severe childhood respiratory infections have been related to asthma commencing at any time in life [16]. To
AFFILIATIONS

*The University of Melbourne, Melbourne, Australia.

\#Imperial College, London, UK "Helmholtz Zentrum München, Neuherberg, Germany.

+University of Bordeaux 2, Bordeaux, France.

§uppsala University, Uppsala, Sweden.

${ }^{f}$ Centre for Environmental Research and

**Institut Municipal d'Investigació Médica, Barcelona, and

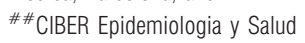

Pública, Spain.

"The University of Bergen, Bergen, Norway.

CORRESPONDENCE

S.C. Dharmage

Centre for Molecular, Environmental, Genetic and Analytic Epidemiology, School of Population Health, The University of Melbourne, Level 1, 723 Swanston Street, Carlton, VIC 3052

Australia

Fax: 6193495815

E-mail: s.dharmage@

unimelb.edu.au

Received:

May 242007

Accepted after revision:

September 272008

SUPPORT STATEMENT

For full details of the funding of this study go to the Acknowledgements section.

STATEMENT OF INTEREST

A statement of interest for this study can be found at www.erj.ersjournals. com/misc/statements.shtml 
date, no studies have examined the longitudinal change of lung function and respiratory symptoms of this high-risk group of adults.

In the present study, data of an $8.9 \mathrm{yr}$ follow-up of a cohort of adults from 28 European centres of the European Community Respiratory Health Survey (ECRHS) was analysed to determine whether severe childhood respiratory infections predict prevalence, incidence and persistence of asthma, level of lung function and change in lung function in young adults.

\section{METHODS}

\section{Study subjects and data collection methods}

The full protocol of the ECRHS has been published in the European Respiratory Journal [17]. Briefly, between 1991-1993, 48 study centres in 22 countries participated in the first round of ECRHS 1 [18], which comprised of two stages. Each participating centre selected a random sample of subjects aged 20-44 yrs from an area defined by pre-existing administrative boundaries with a population of $\geqslant 150,000$. Where possible an up to date sampling frame was used to randomly select a minimum of 1,500 males and 1,500 females. These study subjects were posted a screening questionnaire in ECRHS 1 stage 1. Subsequently, 38 centres invited a random and a symptomatic sample of postal survey participants of ECRHS 1 stage 1 to take part in clinical investigations (ECRHS 1 stage 2). Subjects responded to a detailed a questionnaire including sociodemographic details, respiratory symptoms during the preceding 12 months, allergic symptoms and family history. They also performed baseline spirometry and underwent bronchial challenge with methacholine, and provided a blood sample for measurement of immunoglobulin (Ig)E. On average 8.9 yrs (interquartile range 8.3-9.5 yrs) after the initial investigation, 29 centres re-investigated the participants of the laboratory study using similar methods (ECRHS 2) [19]. The present study included all the centres that participated in both surveys when examining outcomes related to the questionnaire survey but excluded two centres when examining lung function tests. One of these did not conduct lung function tests and the other had methodological issues with the measurements of lung function.

\section{Definitions of respiratory morbidity outcomes}

Adult respiratory morbidity was defined as ever having asthma, current wheeze, lower lung function measurements and changes in asthma status and lung function measurements between ECRHS 1 and ECRHS 2. Participants were classified as having current wheeze in the cross sectional analysis if they answered yes to the question "Have you had wheezing or whistling at any time during the last 12 months?" in the ECRHS 1. Persistent wheeze in the longitudinal analysis was defined if participants answered yes to this question in both ECRHS 1 and ECRHS 2. Participants were classified as having had self-reported asthma in the cross sectional analysis if they answered yes to the question "Have you ever had asthma?" and new selfreported asthma in the longitudinal analysis if they answered yes to this question in ECRHS 2 but not in ECRHS 1. FEV1, forced vital capacity (FVC) and the FEV1/FVC ratio were also used to assess the lung function outcomes.

\section{Definitions of childhood infections}

Exposure to childhood infections was defined using the following two questions: 1) in ECRHS 1 "Did you have a serious respiratory infection (SRI) before 5 yrs of age?" and 2) for ECRHS 2 "Were you hospitalised before 2 yrs of age for lung disease?"

\section{Statistical methods}

The current analysis only included the subjects of the random samples who participated in both ECRHS 1 and ECRHS 2.

Binary measures of asthma and current wheeze (i.e. wheeze during last 12 months), self-reported asthma, persistent wheeze, new current wheeze and new self-reported asthma were considered as outcome variables in the analysis. In addition, continuous measures of lung function, FEV1, FVC and the FEV1/FVC ratio were defined as the outcome variables. The primary exposure variables were SRI aged $<5$ yrs and hospitalisation for lung disease (HLD) aged $<2$ yrs. Confounding effects related to age, sex and social class were adjusted for in all the models and in addition height was included in models on lung function outcome measures. Moreover, variables consistently associated with the exposures at $\mathrm{p}<0.2$ were included as confounders in all the models.

Mixed effects models were used to evaluate the association between exposure and outcome variables. A linear mixed effects model was used for the lung function models and a generalised linear mixed effects model with a binomial distribution and logit link function for binary response variables was considered.

As a first step, crude base models (age and height adjusted for lung function outcomes) were developed with each exposure variable. Confounders were then included and those that made a significant contribution to the final parsimonious models were retained. Parameter estimates from the lung function models may be interpreted as a change in lung function with a change in each exposure variable and corresponding 95\% confidence interval (CI). To examine whether SRI or HLD was associated with a long-term decline in lung function the difference between FEV1 at ECRHS 1 and ECRHS 2 was computed as the outcome. A similar measure was used for FVC and the FEV1/FVC ratio. To determine whether each of the models were correctly specified the Hausman specification test was performed. Results from the binary outcome models are presented as odds ratios with $95 \%$ CI. Data were stratified by sex, current smoking, maternal smoking and maternal asthma and then tested for interactions.

Meta-analyses according to DERSIMONIAN and LAIRD [19] were used to investigate potential heterogeneity between countries in the associations between childhood infections and subsequent adult respiratory morbidity. All statistical tests were two tailed and a p-value $<0.05$ was considered to be statistically significant.

\section{RESULTS}

In total, 9,175 individuals participated in both studies, of which $884(9.6 \%)$ reported SRI aged $<5$ yrs and $224(2.4 \%)$ reported HLD aged $<2$ yrs. Overall, 150 (17\%) of the respondents who reported a SRI aged $<5$ yrs also reported hospitalisation for lung disease aged $<2$ yrs. Only $64(1 \%)$ of the respondents 
who reported not having had an SRI aged $<5$ yrs reported HLD aged $<2$ yrs.

Table 1 illustrates the distribution of indicators of severe childhood respiratory infections and disease outcomes of interest by country of study. There was a substantial variation in the distribution of severe childhood respiratory infections and different asthma outcomes across countries.

Table 2 describes the relevant participants' characteristics by indicators of severe childhood respiratory infections. Maternal smoking and maternal asthma were associated with both indicators of childhood respiratory infections. Reported history of bedroom sharing or nursery/school attendance at $<5$ yrs of age, number of older siblings and personal smoking were not associated with any of the indicators of childhood respiratory infections.

Mixed effects models were developed to evaluate the association between indicators of childhood SRI and lung function measurements (table 3). In a crude (age and height) adjusted mixed effects regression, SRI aged $<5$ yrs was significantly associated with lower FEV1, FVC and FEV1/FVC ratio and this remained a significant predictor of all three measures even after controlling for other confounding variables. Mixed effects regression models for HLD aged $<2$ yrs showed similar findings to SRI aged $<5$ yrs. In both a crude and adjusted analyses of FEV1 and FVC, HLD aged $<2$ yrs was a significant predictor of lower lung function. However, the evidence for an association between HLD aged $<2$ yrs and FEV1/ FVC ratio was modest. Neither SRI aged $<5$ yrs nor HLD aged $<2$ yrs were significantly associated with changes in FEV1, FVC or the FEV1/FVC ratio over 8.9 yrs.

People who were exposed to maternal smoking and had a HLD aged $<2$ yrs, had lower FVC compared with those who were not exposed to maternal smoking and had a HLD. Although the inclusion of an interaction term was of borderline significance $(p=0.09)$ the mixed effects model explained $70 \%$ of the variation in FVC.

Table 4 displays crude and adjusted estimates of exposures to SRI aged $<5$ yrs and HLD aged $<2$ yrs separately, from a mixed effects regression models for asthma and wheeze. SRI aged $<5$ yrs was significantly associated with an increased risk of self-reported asthma, new self-reported asthma, current wheeze and persistent wheeze. Similarly, there was strong evidence that HLD aged $<2$ yrs was associated with selfreported asthma, current wheeze and persistent wheeze. There was some evidence that SRI aged $<5$ yrs and HLD aged $<2$ yrs were associated with new current wheeze and HLD aged $<2$ yrs was associated with new self-reported asthma.

People who currently smoke and had an SRI in $<5$ yrs of age were at a higher risk of having new self-reported asthma in the follow-up $(\mathrm{p}<0.001)$ compared with those who do not smoke and had an SRI in $<5$ yrs of age. The interaction term was significant $(\mathrm{p}=0.02)$.

To examine the temporality of the association, the analysis on the association between SRI and HLD on asthma, wheeze and lung function was repeated after excluding those who developed asthma before 5 yrs of age (see online supplementary material table $3 \mathrm{~b}$ and table $4 \mathrm{~b}$ ). In total, $20 \%$ of the 1,247 participants who have previously had or have asthma, reported their first attack of asthma before $<5$ yrs of age. The results were consistent between the analyses.

To examine the recall bias, those with self-reported asthma or current wheeze in 1992 were excluded and repeated the analysis on the association between SRI, HLD and lung function in 1992 (see online supplementary material table 3c). Results were consistent between the two analyses.

The meta-analysis demonstrated that the associations between SRI and HLD and respiratory outcomes were consistent across

TABLE 1 Distribution of childhood respiratory infections and asthma outcomes by country

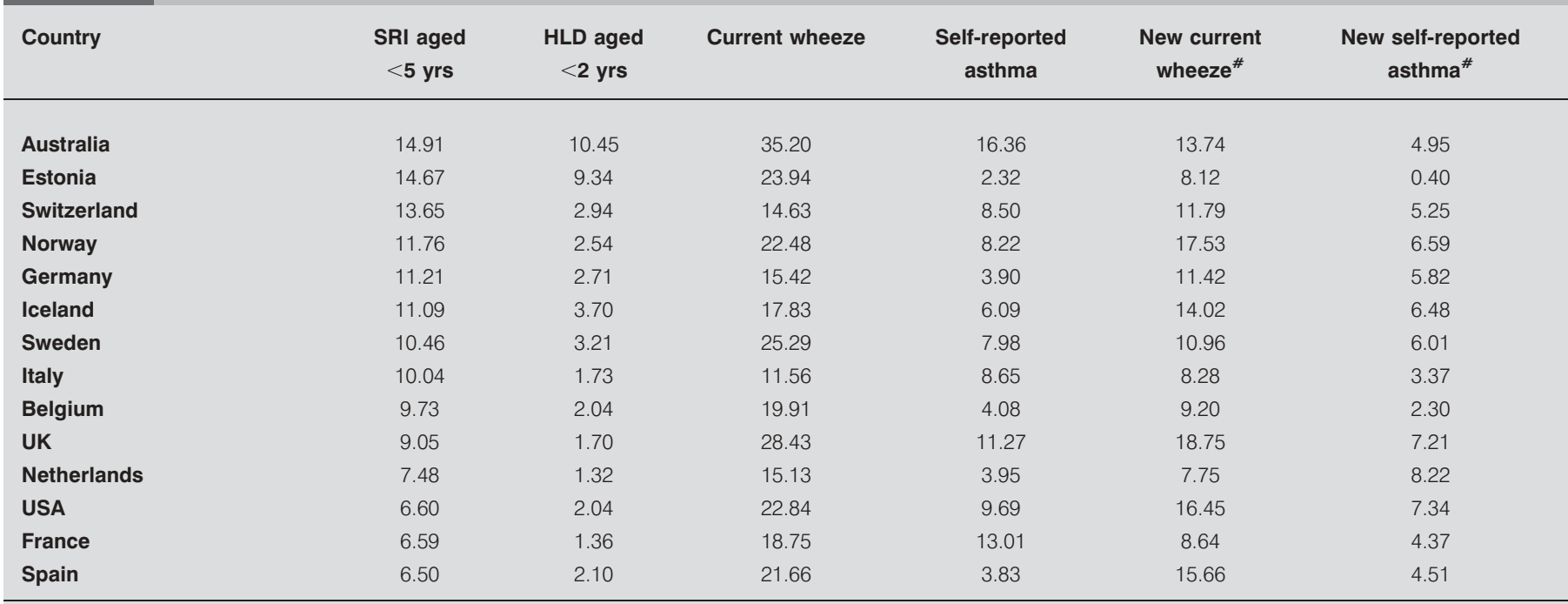

SRI: serious respiratory infection; HLD: hospitalisation for lung disease. ${ }^{\#:}$ included who did not report the relevant outcome in European Community Respiratory Health Survey (ECRHS) 1 but reported in ECRHS 2. 


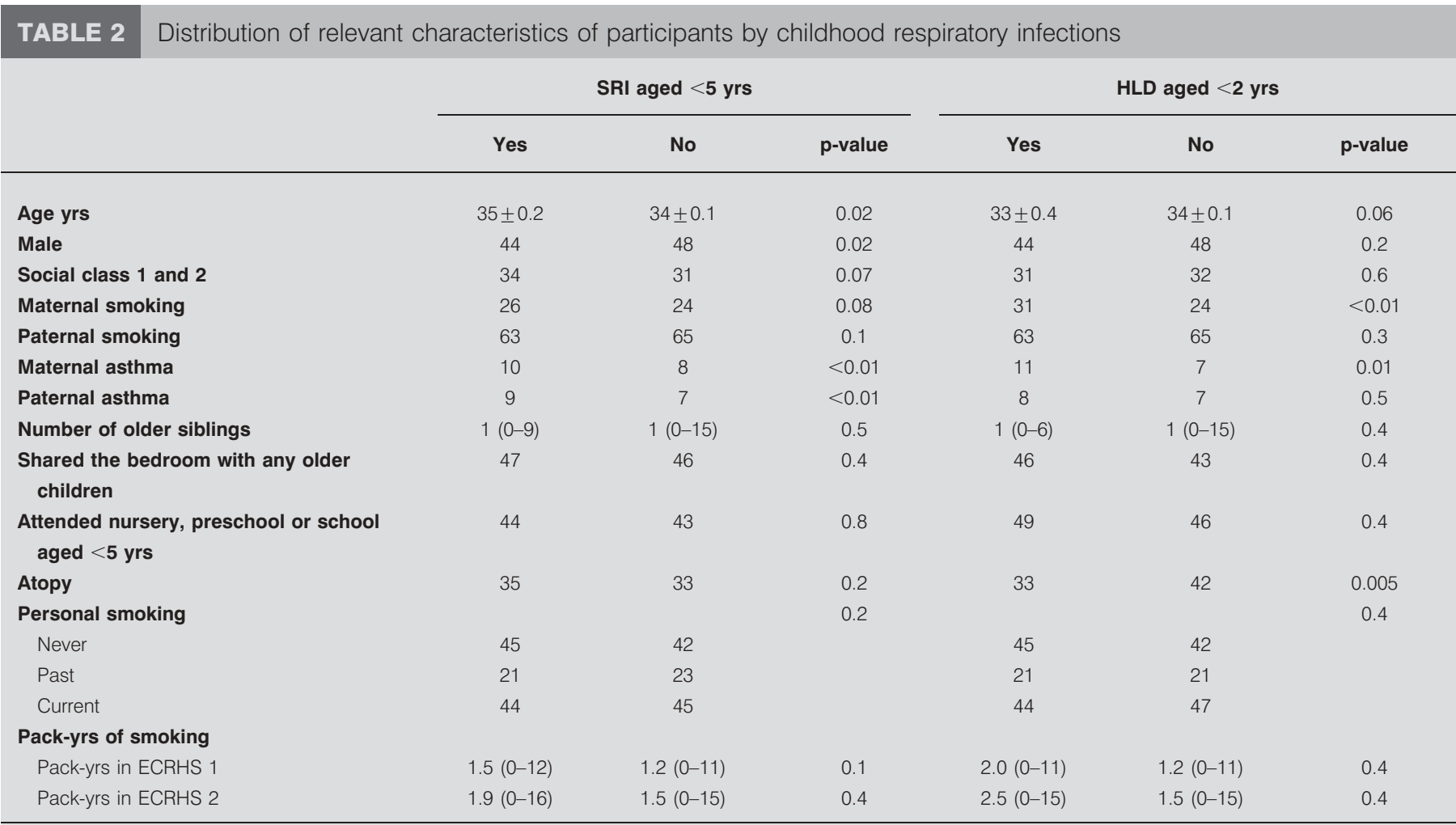

Data are presented as mean \pm SD, \% or median (interquartile range), unless otherwise stated. SRI: serious respiratory infections; HLD: hospitalisation for lung disease; ECRHS: European Community Respiratory Health Survey.

centres ( $\mathrm{p}_{\text {heterogeneity }}>0.05$; see online supplementary material figs 1 and 2).

\section{DISCUSSION}

Adults reporting severe childhood respiratory infections had more asthma and wheeze, continued to wheeze and developed more new asthma and wheeze in adult life than controls during $9 \mathrm{yrs}$ of follow-up. Severe childhood respiratory infections were also associated with a lower level of adult lung function, but were not related to lung function decline. The findings were consistent between centres with a different prevalence of childhood infections, and an association with lung function was also present when excluding all subjects with asthma and current wheeze. Childhood respiratory infections were a stronger predictor for adult respiratory morbidity among subjects exposed to maternal or active smoking.

The first 3-4 yrs of life is a time characterised by multiplication of alveoli and growth of the bronchi [20]. The present findings suggest that serious respiratory infections during this critical period of lung development may cause permanent changes making lung function suboptimal, which may be carried over to adult life. This is in accordance with literature showing that young adults with a past history of bronchiolitis or pneumonia had lower lung function and more respiratory symptoms than those without such a history [5, 10, 11, 13, 14]. It could be argued that having early respiratory infections is a marker of asthma [7]. However, the current subgroup analysis on lung function restricted to those who never had asthma produced similar results to the main analysis contradicting this argument. This agrees with the study by JOHNSTON et al. [13] showing that childhood pneumonia was related to poor lung function in adults with no history of wheeze.

Maternal smoking was higher among those with childhood respiratory infections. The impact of HLD aged $<2$ yrs on FVC was greater among those whose mothers smoked. Similarly, SRI aged $<5$ yrs was a significant predictor of new selfreported asthma only among current smokers. These findings may suggest that further environmental insults to the lungs are likely to compound the damage already caused by respiratory infections. Such compounding effects may explain the associations between respiratory infections and impaired lung function growth in children [8], asthma starting at any time in life [16] and the development of new asthma and wheeze over the 8-yr follow-up in the present study.

Early viral respiratory infections have been suggested to lead to allergic sensitisation by 3 yrs of age and therefore to the development of asthma [21]. Some studies suggest that atopy prone children may develop more prominent symptoms with infections, which present as serious respiratory infection [3]. A higher prevalence of atopy, defined using specific IgE levels among those who had been hospitalised for lung disease but not among those who had a serious respiratory infection before 5 yrs of age was observed. Similarly, allergic sensitisation in children aged $>7$ yrs $[4,5,7,10]$ or young adults $[4,5,7,10]$ was related neither to childhood lower respiratory infections $[4,5,7,10]$ nor to doctor treated airway disease $[4,5,7,10]$. 


\begin{tabular}{|c|c|c|c|c|c|}
\hline \multirow[t]{2}{*}{ TABLE 3} & \multicolumn{5}{|c|}{$\begin{array}{l}\text { Association between serious respiratory infection } \\
\text { (SRI) aged }<5 \text { yrs, hospitalisation for lung } \\
\text { disease (HLD) at }<2 \text { yrs of age and lung function } \\
\text { measurements in 1992: mixed effects regression } \\
\text { model }\end{array}$} \\
\hline & & $\begin{array}{l}\text { Mean of the } \\
\text { outcome }\end{array}$ & $\begin{array}{l}\text { Difference in } \\
\text { the outcome }\end{array}$ & $95 \% \mathrm{Cl}$ & p-value \\
\hline \multicolumn{6}{|l|}{ FEV1 $\mathrm{mL}$} \\
\hline \multicolumn{6}{|c|}{ SRI aged $<5$ yrs } \\
\hline Yes & & 3600 & & & \\
\hline No & & 3750 & & & \\
\hline Crude $^{\#}$ & & & $-99 \pm 19$ & $-137--61$ & $<0.001$ \\
\hline Adjusted" & & & $-89 \pm 18$ & $-126--54$ & $<0.001$ \\
\hline \multicolumn{6}{|c|}{ HLD aged $<2$ yrs } \\
\hline Yes & & 3620 & & & \\
\hline No & & 3740 & & & \\
\hline Crude $^{\#}$ & & & $-145 \pm 35$ & $-214--76$ & $<0.001$ \\
\hline Adjusted ${ }^{\circ}$ & & & $-144 \pm 33$ & $-211--78$ & $<0.001$ \\
\hline \multicolumn{6}{|c|}{ FVC mL } \\
\hline \multicolumn{6}{|c|}{ SRI aged $<5$ yrs } \\
\hline Yes & & 4460 & & & \\
\hline No & & 4570 & & & \\
\hline Crude $^{\#}$ & & & $-57 \pm 0.022$ & $-101--14$ & 0.01 \\
\hline Adjusted ${ }^{\circ}$ & & & $-49 \pm 0.021$ & $-90--8$ & 0.02 \\
\hline \multicolumn{6}{|c|}{ HLD aged $<2$ yrs } \\
\hline Yes & & 4450 & & & \\
\hline No & & 4570 & & & \\
\hline Crude $^{\#}$ & & & $-137 \pm 40$ & $-216--58$ & 0.001 \\
\hline Adjusted ${ }^{\circ}$ & & & $-145 \pm 38$ & $-220--70$ & $<0.001$ \\
\hline \multicolumn{6}{|l|}{$\mathrm{FEV}_{1} /$ FVC $\%$} \\
\hline \multicolumn{6}{|c|}{ SRI aged $<5$ yrs } \\
\hline Yes & & 80.98 & & & \\
\hline No & & 82.42 & & & \\
\hline Crude $^{\#}$ & & & $-1.185 \pm 0.240$ & $-1.656--0.714$ & $<0.001$ \\
\hline Adjusted" & & & $-1.191 \pm 0.309$ & $-1.798--0.586$ & $<0.001$ \\
\hline \multicolumn{6}{|c|}{ HLD aged $<2$ yrs } \\
\hline Yes & & 81.39 & & & \\
\hline No & & 82.31 & & & \\
\hline Crude $^{\#}$ & & & $-0.857 \pm 0.437$ & $-1.715-0.0002$ & 0.05 \\
\hline Adjusted" & & & $-0.709 \pm 0.451$ & $-1.593-0.175$ & 0.12 \\
\hline
\end{tabular}

Data are expressed as coefficient $\pm \mathrm{SE}$, unless otherwise stated. Cl: confidence interval; FEV1: forced expiratory volume in one second; FVC: forced vital capacity. "\#: controlling for age and height; ": controlling for age, height, sex, maternal smoking, maternal asthma, social class and random effects for centre.

The current study has many methodological strengths. The large sample size provided sufficient power to investigate rare events such as HLD and SRI. Objective measures of respiratory morbidity were collected via lung function testing. Results can be generalised widely as the study was conducted across many countries, and the fact that the findings were consistent across centres with a different prevalence of SRI and HLD strengthen the conclusion that there is an underlying biological effect.

The main limitation of the study is related to the retrospective collection of information on childhood respiratory infections. A study of adults reporting on childhood pets twice 9 yrs apart
TABLE 4 Association between serious respiratory infection (SRI) aged $<5$ yrs, hospitalisation for lung disease (HLD) at $<2$ yrs of age and indicators of asthma: mixed effects regression model

\begin{tabular}{|c|c|c|c|c|}
\hline & Subjects & OR & $95 \% \mathrm{Cl}$ & $\mathrm{p}$-value \\
\hline \multicolumn{5}{|c|}{ Self-reported asthma } \\
\hline \multicolumn{5}{|c|}{ SRI aged $<5$ yrs } \\
\hline Yes & 259 (22.70) & & & \\
\hline No & $882(77.30)$ & & & \\
\hline Crude & & 2.61 & $2.22-3.07$ & $<0.001$ \\
\hline Adjusted $^{\#}$ & & 2.53 & $2.14-3.00$ & $<0.001$ \\
\hline \multicolumn{5}{|c|}{ HLD aged $<2$ yrs } \\
\hline Yes & $87(7.04)$ & & & \\
\hline No & $1149(92.96)$ & & & \\
\hline Crude & & 3.58 & $2.72-4.72$ & $<0.001$ \\
\hline Adjusted $^{\#}$ & & 3.51 & $2.63-4.67$ & $<0.001$ \\
\hline \multicolumn{5}{|c|}{ New self-reported asthma } \\
\hline \multicolumn{5}{|c|}{ SRI aged $<5$ yrs } \\
\hline Yes & $62(13.51)$ & & & \\
\hline No & 397 (86.49) & & & \\
\hline Crude & & 1.47 & $1.11-1.95$ & 0.007 \\
\hline Adjusted $^{\#}$ & & 1.48 & $1.03-1.85$ & 0.03 \\
\hline \multicolumn{5}{|c|}{ HLD aged $<2$ yrs } \\
\hline Yes & $16(3.29)$ & & & \\
\hline No & 470 (96.71) & & & \\
\hline Crude & & 1.58 & $0.93-2.68$ & 0.09 \\
\hline Adjusted ${ }^{\#}$ & & 1.60 & $0.94-2.73$ & 0.08 \\
\hline \multicolumn{5}{|c|}{ Current wheeze } \\
\hline \multicolumn{5}{|c|}{ SRI aged $<5$ yrs } \\
\hline Yes & $410(16.86)$ & & & \\
\hline No & $2022(83.14)$ & & & \\
\hline Crude & & 1.92 & $1.67-2.21$ & $<0.001$ \\
\hline Adjusted $^{\#}$ & & 1.91 & $1.65-2.20$ & $<0.001$ \\
\hline \multicolumn{5}{|c|}{ HLD aged $<2$ yrs } \\
\hline Yes & $115(4.41)$ & & & \\
\hline No & $2494(95.59)$ & & & \\
\hline Crude & & 1.98 & $1.53-2.55$ & $<0.001$ \\
\hline Adjusted ${ }^{\#}$ & & 1.95 & $1.49-2.54$ & $<0.001$ \\
\hline
\end{tabular}

Persistent wheeze

SRI aged $<5$ yrs

$\begin{array}{lc}\text { Yes } & 270(18.24) \\ \text { No } & 1210(81.76)\end{array}$

Crude

Adjusted $^{\#}$

HLD aged $<2$ yrs

Yes

No

Crude

Adjusted\#

$1.95 \quad 1.49-2.54 \quad<0.001$

$\begin{array}{lll}1.34 & 1.06-1.69 & 0.01 \\ 1.31 & 1.02-1.66 & 0.03\end{array}$

$87(5.39)$

$1527(94.61)$

$\begin{array}{lll}2.11 & 1.35-3.28 & 0.001 \\ 2.24 & 1.40-3.57 & 0.001\end{array}$

New current wheeze

SRl aged $<5$ yrs
Yes
No
Crude
Adjusted $^{\#}$
HLD aged $<2$ yrs
Yes
No
Crude
Adjusted $^{\#}$

$95(10.97)$

$771(89.03)$

$\begin{array}{lll}1.21 & 0.96-1.53 & 0.11 \\ 1.23 & 0.97-1.57 & 0.09\end{array}$

$28(3.01)$

903 (96.99)

$\begin{array}{lll}1.46 & 0.96-2.23 & 0.08 \\ 1.53 & 0.99-2.36 & 0.05\end{array}$

Data are presented as $\mathrm{n}$ (\% with the outcome), unless otherwise stated. OR odds ratio; $\mathrm{Cl}$ : confidence interval. ${ }^{\#}$ : controlling for age, sex, maternal smoking, maternal asthma, social class and random effects for centre. 
showed a high reliability in adults reporting on a childhood event; however, some degree of nondifferential misclassification was present [22]. The fact that almost all subjects reporting HLD in ECRHS 2 had reported serious childhood infections 9 yrs earlier in ECRHS 1 suggest that the reporting is relatively reliable. Conversely, concerning childhood infections, asthmatics may recall early infections more accurately, thus causing differential misclassification and a spurious association between childhood infections and the indicators of asthma. However, the present results on the association between childhood infections and adult lung function were reproduced in the analysis restricted to subjects without any history of asthma and current wheeze. Furthermore, recall error when assessing childhood infections (SRI) in ECRHS 1 is unlikely to have affected reporting of subsequent onset of asthma or wheeze 9 yrs later. Thus, it seems unlikely that the observed associations between childhood respiratory infections and measures of respiratory morbidity are entirely explained by recall bias.

The current findings have important clinical practice, public health and research implications. Clinicians as well as adults with a past history of serious childhood respiratory infections should be made aware of the possible increased risk of chronic respiratory health problems. Findings of the present study highlight the importance of primary prevention of childhood respiratory infections through immunisations. Given that the adverse impact of serious childhood respiratory infections was aggravated by maternal and personal smoking, the current authors suggest that every effort should be made to discourage parental and personal smoking among those with such a history. Further studies are required to gain a better insight into the nature and mechanism of the on going alteration in airway function related to childhood respiratory infections.

\section{ACKNOWLEDGEMENTS}

The European Community Respiratory Health Survey (ECRHS) study is a joint project involving many participants and is funded by many sources. The staff involved in the ECRHS study were as follows: P. Burney (project leader); S. Chinn (statistician); D. Jarvis and C. Luczynska (principal investigators); J. Knox (project co-ordinator); J. Potts (assistant statistician); and S. Arinze (data manager; all National Heart and Lung Institute, Imperial College, London, UK).

The investigators in the Early life Working Group in ECRHS are as follows: C. Svanes (Chair); S. Dharmage (Melbourne, Australia); T. Gislason (Reykjavik, Iceland); M. Gunnbjørnsdottir (Uppsala, Sweden); J. Heinrich (Neuherberg, Germany); D. Jarvis (London, UK); B. Leynaert (Paris, France); D. Ludvigsdottir (Reykjavik, Iceland); R. de Marco, (Verona, Italy); F. Neukirch (Paris, France); C. Raherison (Paris, France); J. Sunyer (Barcelona, Spain); S. Villani (Pavia, Italy); and M. Wjst (Neuherberg, Germany).

The Principal Investigators and Senior Scientific Team in ECRHS are as follows: P. Vermeire, J. Weyler, M. Van Sprundel, V. Nelen (South Antwerp and Antwerp City, Belgium); R. Jogi, A. Soon (Tartu, Estonia); F. Neukirch, B. Leynaert, R. Liard, M. Zureik (Paris, France); I. Pin, J. FerranQuentin (Grenoble, France); J. Heinrich, M. Wjst, C. Frye, I.
Meyer (Erfurt, Germany); T. Gislason, E. Bjornsson, D. Gislason, T. Blondal, K.B. Jorundsdottir (Reykjavik, Iceland); M. Bugiani, P. Piccioni, E. Caria, A. Carosso, E. Migliore, G. Castiglioni (Turin, Italy); R. de Marco, G. Verlato, E. Zanolin, S. Accordini, A. Poli, V. Lo Cascio, M. Ferrari (Verona, Italy); A. Marinoni, S. Villani, M. Ponzio, F. Frigerio, M. Comelli, M. Grassi, I. Cerveri, A. Corsico (Pavia, Italy); J. Schouten (Groningen, the Netherlands); M Kerkhof (Geleen, the Netherlands); A. Gulsvik, E. Omenaas, C. Svanes, B. Laerum (Bergen, Norway); J.M. Antó, J. Sunyer, M. Kogevinas, J.P. Zock, X. Basagana, A. Jaen, F. Burgos (Barcelona, Spain); J. Maldonado, A. Pereira, J.L. Sanchez (Huelva, Spain); J. Martinez-Moratalla Rovira, E. Almar (Albacete, Spain); N. Muniozguren, I. Urritia (Galdakao, Spain); F. Payo (Oviedo, Spain); C. Janson, G. Boman, D. Norback, M. Gunnbjornsdottir (Uppsala, Sweden); K. Toren, L. Lillienberg, A.C. Olin, B. Balder, A. Pfeifer-Nilsson, R. Sundberg (Gothenburg, Sweden); E. Norrman, M. Soderberg, K. Franklin, B. Lundback, B. Forsberg, L. Nystrom (Umeå, Sweden); N. Künzli, B. Dibbert, M. Hazenkamp, M. Brutsche, U. Ackermann-Liebrich (Basel, Switzerland); D. Jarvis, B. Harrison (Norwich, UK); D. Jarvis, R. Hall, D. Seaton (Ipswich, UK).

S.C. Dharmage was supported by the National Health Medical Research Council, Australia.

The coordination of ECRHS II was supported by the European Commission, as part of their Quality of Life programme. The following bodies funded the local studies in ECRHS II in this study.

Albacete Fondo de Investigaciones Santarias (grant code: 97/ 0035-01, 99/0034-01 and 99/0034-02), Hospital Universitario de Albacete, Consejeria de Sanidad (Albacete); Basque Health Department (Galdakao); Fondo de Investigaciones Sanitarias (grant code: 99/0034-01 and 99/0034-02), Red Respira (RTIC 03/11 ISC IIF; Barcelona); Fondo de Investigaciones Sanitarias (FIS; grant code: 97/0035-01, 99/0034-01 and 99/0034-02; Huelva, Spain). FWO (Fund for Scientific Research)-Flanders Belgium (grant code: G.0402.00), University of Antwerp, Flemish Health Ministry (Antwerp, Belgium). Swiss National Science Foundation, Swiss Federal Office for Education and Science, Swiss National Accident Insurance Fund (Basel, Swizerland). Norwegian Research Council, Norwegian Asthma and Allergy Association, Glaxo Wellcome AS, Norway Research Fund (Bergen, Norway). Institut Pneumologique d'Aquitaine (Bordeaux); Programme Hospitalier de Recherche Clinique-DRC de Grenoble, Ministry of Health, Direction de la Recherche Clinique, Ministere de 1'Emploi et de la Solidarite, Direction Generale de la Sante, CHU de Grenoble, Comite des Maladies Respiratoires de l'Isere (Grenoble); Programme Hospitalier de Recherche Clinique-DRC de Grenoble, Ministry of Health, Direction de la Recherche Clinique, CHU de Grenoble, Ministere de 1'Emploi et de la Solidarite, Direction Generale de la Sante, Aventis, Direction Régionale des Affaires Sanitaires et Sociales Languedoc-Roussillon, Oviedo Fondo de Investigaciones Santarias (grant code: 97/0035-01, 99/003401 and 99/0034-02; Montpellier); Ministere de l'Emploi et de la Solidarite, Direction Generale de la Sante, UCBPharma, Aventis, GlaxoSmithKline France, Programme Hospitalier de 
Recherche Clinique-DRC de Grenoble, Ministry of Health, Direction de la Recherche Clinique, CHU de Grenoble (Paris, France). GSF National Research Centre for Environment and Health, Deutsche Forschungsgemeinschaft (DFG; grant code FR 1526/1-1; Erfurt); GSF National Research Centre for Environment and Health, Deutsche Forschungsgemeinschaft (grant code MA 711/4-1; Hamburg, Germany). Swedish Heart Lung Foundation, Swedish Foundation for Health Care Sciences and Allergy Research, Swedish Asthma and Allergy Foundation, Swedish Cancer and Allergy Foundation (Gothenburg, Sweden); Swedish Heart Lung Foundation, Swedish Foundation for Health Care Sciences and Allergy Research, Swedish Asthma and Allergy Foundation, Swedish Cancer and Allergy Foundation (Umeå); Swedish Heart Lung Foundation, Swedish Foundation for Health Care Sciences and Allergy Research, Swedish Asthma and Allergy Foundation, Swedish Cancer and Allergy Foundation (Uppsala, Sweden). National Asthma Campaign (Ipswich and Norwich, UK). GlaxoSmithKline Italy, Italian Ministry of University and Scientific and Technological Research, Local University Funding for Research 1998 and 1999 (Pavia, Italy); ASL 4 Regione Piemonte, AO CTO/ICORMA Regione Piemonte, Ministero dell'Università e della Ricerca Scientifica (Turin, Italy); Glaxo Wellcome Spa, University of Verona, Italian Ministry of University and Scientific and Technological Research, GlaxoSmithKline Italy (Verona, Italy). American Lung Association of Oregon, Northwest Health Foundation, Collins Foundation, Merck Pharmaceutical (Portland, USA). Icelandic Research Council, Icelandic University Hospital Fund (Reykjavik, Iceland). Estonian Science Foundation (Tartu, Estonia).

The following bodies funded ECRHS I for centres in ECRHS II. Asthma Foundation of Victoria, Allen and Hanburys (Australia). Belgian Science Policy Office, National Fund for Scientific Research (Belgium). Ministère de la Santé, GlaxoSmithKline France, Institut Pneumologique d'Aquitaine, Contrat de Plan Etat-Région LanguedocRousillon, CNMATS, CNMRT (90MR/10, 91AF/6), Ministre delegué de la santé, RNSP (France). GSF and the Bundesminister für Forschung und Technologie (Bonn, Germany). Ministero dell'Università e della Ricerca Scientifica e Tecnologica, Consiglio Nazionale dell Ricerche, Regione Veneto grant RSF no. 381/05.93 (Italy). Norwegian Research Council project no. 101422/310 (Norway). Dutch Ministry of Wellbeing, Public Health and Culture (the Netherlands). Ministerio de Sanidad y Consumo FIS (grants 91/0016060/00E-05E and 93/0393) and grants from Hospital General de Albacete, Hospital General Juan Ramón Jiménez, Consejería de Sanidad, Principado de Asturias (Spain). The Swedish Medical Research Council, the Swedish Heart Lung Foundation, the Swedish Association against Asthma and Allergy (Sweden). Swiss National Science Foundation grant 4026-28099 (Swizerland). National Asthma Campaign, British Lung Foundation, Department of Health, South Thames Regional Health Authority (UK). United States Department of Health, Education and Welfare Public Health Service (grant 2 S07 RR05521-28).

The following centres took part at their own expense: M. Abramson, S. Dharmage, J. Raven, E.H. Walters (Melbourne,
Australia); A. Taytard, C. Raherison (Bordeaux, France); J. Bousquet, P. Demoly (Montpellier, France); K. Richter (Hamburg, Germany); M. Osborne, S. Buist, W. Vollmer and L. Johnson (Portland, USA).

\section{REFERENCES}

1 Everard ML. The relationship between respiratory syncytial virus infections and the development of wheezing and asthma in children. Curr Opin Allergy Clin Immunol 2006; 6: 56-61.

2 Arshad SH, Kurukulaaratchi RJ, Fenn M, Mathews S. Early life risk factors for current wheeze, asthma and BHR at 10 years of age. Chest 2005; 28: 502-508.

3 Ponsonby A, Cooper D, Dwyer T, Carmichael A, Kemp A. Relationship between early life respiratory illness, family size over time, and the development of asthma and hay fever: a seven year follow-up study. Thorax 1999; 54: 664-669.

4 Stein RT, Sherrill D, Morgan WJ, et al. Respiratory syncytial virus in early life and risk of wheeze and allergy by age 13 years. Lancet 1999; 354: 541-545.

5 Illi S, Mutius Ev, Lau S, et al. Early childhood infectious diseases and the development of asthma up to school age: a birth cohort study. BMJ 2001; 322: 390-395.

6 Dik N, Tate RB, Manfreda J, Anthony NR. Risk of physician diagnosed asthma in the first 6 years of life. Chest 2006; 126: 1147-1153.

7 Meer G, Janssen NAH, Brunekreef B. Early childhood environment and atopic disease. Allergy 2006; 60: 619-625.

8 Gold DR, Tager IB, Weiss ST, Tosteson TD, Speizer FE. Acute lower respiratory illness in childhood as a predictor of lung function and chronic respiratory symptoms. Am Rev Respir Dis 1989; 140: 877-884.

9 Svanes C, Omenaas E, Eide GE, Fluge Ø, Gulsvik A. Hospitalisation for lung disease in early childhood and asthma symptoms in young adults. Respir Med 1998; 92: 1003-1009.

10 Gomez R, Colas C, Sebastian A, Arribas J. Respiratory repercussions in adults with a history of infantile bronchiolitis. Ann Allergy Asthma Immunol 2004; 93: 447-451.

11 Larouche V, Rivard G, Deschesnes F, Goulet R, Turcotte H, Boulet IP. Asthma and airway hyper-responsiveness in adults who required hospital admission for bronchiolitis in early childhood. Respir Med 2000; 94: 288-294.

12 Korpi M, Piipo-Savolainen E, Korhonen K, Remes S. Respiratory morbidity 20 years after RSV infection in infancy. Pediatr Pulmonol 2004; 38: 155-160.

13 Johnston ID, Strachan DP, Anderson HR. Effect of pneumonia and whooping cough in childhood on adult lung function. N Engl J Med 1998; 338: 581-587.

14 Shaheen SO, Sterne JA, Tucker JS, Florey CD. Birth weight, childhood lower respiratory tract infection, and adult lung function. Thorax 1998; 53: 549-553.

15 Shaheen SO, Barker DJP, Shiell AW, Crocker FJ, Wield GA, Holgate ST. The relationship between pneumonia in early childhood and impaired lung function in late adult life. Am J Respir Crit Care Med 1994; 149: 616-619.

16 Marco Rd, Pattaro C, Locatelli F, Svanes C. Influence of early life exposures on incidence and remission of asthma throughout life. J Allergy Clin Immunol 2004; 113: 845-852. 
17 Burney PG, Luczynska C, Chinn S, Jarvis D. The European Community Respiratory Health Survey. Eur Respir J 1994; 7: 954-960.

18 European Respiratory Health Survey Steering Committee. The European Respiratory Health Survey 11. Eur Respir J 2002; 20: 1071-1079.

19 Dersimonian R, Laird N. Meta-analysis in clinical trials. Control Clin Trials 1986; 7: 177-188.

20 Dezateux C. Lung development and early origins of childhood respiratory illness. Br Med Bull 1997; 53: 40-57.
21 Sigures N, Bjarnason R, Sigurbergsson F, Kjellman B, Bjorksten B. Asthma and immunoglobulin E antibodies after respiratory syncytial virus bronchiolitis: a prospective cohort study with matched controls. Pediatrics 1995; 95: 500-505.

22 Svanes C, Dharmage S, Sunyer J, et al. Long-term reliability in reporting of childhood pets by adults interviewed twice, nine years apart. Results from the European Community Respiratory Health Survey I and II. Indoor Air 2008; 218: 84-92. 